Article

\title{
Structure and Properties of a Metallocene Polypropylene Resin with Low Melting Temperature for Melt Spinning Fiber Application
}

\author{
Renwei Xu ${ }^{1}$, Peng Zhang ${ }^{1}$, Hai Wang ${ }^{1, *}, \mathrm{Xu} \mathrm{Chen}^{1}$, Jie Xiong ${ }^{2}$, Jinpeng $\mathrm{Su}^{3}$, Peng Chen ${ }^{3,4, *}$ \\ and Zhicheng Zhang ${ }^{2, * \mathbb{D}}$ \\ 1 Lanzhou Petrochemical Research Center, Petrochina, Lanzhou 730060, China; \\ xurenwei@petrochina.com.cn (R.X.); zhangpeng931@petrochina.com.cn (P.Z.); \\ chenxu001@petrochina.com.cn (X.C.) \\ 2 Xi'an Key Laboratory of Sustainable Energy Materials Chemistry; Department of Applied Chemistry; \\ School of Science; Xi'an Jiaotong University; Xi'an 710049, China; xiongjiely@stu.xjtu.edu.cn \\ 3 Ningbo Key Laboratory of Polymer Materials, Ningbo Institute of Materials Technology and \\ Engineering (NIMTE), CAS, Ningbo 315201, China; sujinpeng@nimte.ac.cn \\ 4 Center of Materials Science and Optoelectronics Engineering, University of Chinese Academy of Sciences, \\ Beijing 100049, China \\ * Correspondence: wanghai2@petrochina.com.cn (H.W.); pchen@nimte.ac.cn (P.C.); \\ zhichengzhang@mail.xjtu.edu.cn (Z.Z.); Tel.: +86-29-82668546 (H.W. \& P.C. \& Z.Z.)
}

Received: 11 March 2019; Accepted: 15 April 2019; Published: 22 April 2019

\begin{abstract}
An isotactic polypropylene (iPP-1) resin with low melting temperature $\left(T_{\mathrm{m}}\right)$ is synthesized by a metallocene catalyst and investigated for melt-spun fiber applications. The structure, thermal and mechanical properties, and feasibility of producing fibers of a commercial metallocene iPP (iPP-2) and a conventional Ziegler-Natta iPP (iPP-3) are carefully examined for comparison. $T_{\mathrm{m}}$ of iPP-1 is about $10^{\circ} \mathrm{C}$ lower than the other two samples, which is well addressed both in the resin and the fiber products. Besides, the newly developed iPP-1 possesses higher isotacticity and crystallinity than the commercial ones, which assures the mechanical properties of the fiber products. Thanks to the addition of calcium stearate, its crystal grain size is smaller than those of the two other commercial iPPs. iPP-1 shows a similar rheological behavior as the commercial ones and good spinnability within a wide range of take-up speeds $(1200-2750 \mathrm{~m} / \mathrm{min})$. The tensile property of fibers from iPP-1 is better than commercial ones, which can fulfill the application requirement. The formation of the mesomorphic phase in iPP-1 during melt spinning is confirmed by the orientation and crystallization investigation with wide angle X-ray diffraction (WAXD), which is responsible for its excellent processing capability and the mechanical properties of the resultant fibers. The work may provide not only a promising candidate for the high-performance PP fiber but also a deep understanding of the formation mechanism of the mesomorphic phase during fiber spinning.
\end{abstract}

Keywords: metallocene isotactic polypropylene; melt-spinning; polypropylene fibers

\section{Introduction}

The majority of nonwoven polyolefin fibers are of great commercial interest because of their unique properties, including hydrophobicity, good mechanical properties, and excellent chemical resistance [1,2]. Among them, fibers fabricated from isotactic polypropylene (iPP) are one of the lightest and most widely utilized. Traditional commercial iPP is generally polymerized with a heterogeneous titanium-based Ziegler-Natta catalyst, whose tacticity, molecular weight $\left(\mathrm{M}_{\mathrm{w}}\right)$, and polymer dispersity index (PDI) are tightly dependent on the catalysts and the polymerization 
conditions [3,4]. The development of metallocene catalytic systems offers new access for both the isospecific polymerization of olefins and the new polymer microstructures thanks to the single-site nature of metallocene catalysts. The metallocene polyolefins exhibit interesting physical properties, which are not attainable with conventional Ziegler-Natta catalysts [5]. In comparison with the Ziegler-Natta-catalyzed polypropylene (PP), metallocene polypropylenes are uniform polymers with precisely controlled $\mathrm{M}_{\mathrm{w}}$, end groups, stereoregularity, and narrow PDI [6]. Those characters make metallocene-based iPP a great candidate for producing high-quality industrial fibers by melt spinning.

Crystallization plays a crucial role in determining the structure of not only the iPP resin but also the resulting fibers [7]. Investigations on crystalline structures have revealed that the crystalline phase of iPP fibers is usually composed of the $\alpha$ phase crystal. The $\alpha$ form, which can be easily obtained by the crystallization of polymer in melts or solutions, is the most stable and the most common form in different iPP products [4]. The $\beta$ form, which is produced during the crystallization of a sheared melt, crystallization in a temperature gradient, or during the addition of certain nucleating agents, has to be achieved under well-controlled conditions in iPP products [8]. The $\gamma$ phase is usually formed at high pressure and favored by the low-molecular-weight fraction of polydisperse melts $[9,10]$. In addition to these crystal phases, a mesomorphic phase could be obtained at high cooling rates, which is usually formed during high-speed spinning [11,12]. The mesomorphic phase is characterized by an order intermediate between those found in crystalline and in amorphous phases. However, the structure of this phase has been a matter of debate since its initial report. The mesomorphic phase is composed of bundles of parallel chains, which are typically observed in all polymorphic forms of the threefold helical conformation of PP. Bundles are terminated in the direction of the chain axis by helix reversals or other conformational defects [13]. In the bundles, long-range ordering is maintained only along the chain axes, whereas a large amount of disorder is present in lateral packing [3].

The melt spinning of iPP into fibers has been intensively studied during past decades [14-16]. The fiber structure is mainly formed during crystallization, which starts below the spinneret orifices, in the cooling zone through the solidification of an extruded stream. During fiber formation, crystallization occurs under nonisothermal conditions and high tensile stress, and the cooling rate and tensile stress strongly affect the crystallization of iPP [17]. At low take-up speeds, the cooling rate and the applied tensile stress are low, and the crystallization proceeds at relatively high temperatures, which favors the formation of a monoclinic $\alpha$ crystal in as-spun fibers. As the take-up speed increases, the cooling rate is enhanced, and the crystallization temperature decreases. Structures with high mesomorphic phase content are formed in major during crystallization under such conditions [18-20].

The melt-spinning of metallocene catalyst iPP has been investigated in the last period, Bond and Spruiell demonstrated that the molecular weight and molecular weight distribution (MWD) of metallocene iPP resins had a significant influence on the development of the structure and properties of fibers prepared from these resins. Compared to the Ziegler-Natta-catalyzed resins with similar average molecular weight, the narrower MWD of metallocene resins appeared to be the primary factor that produced differences in the structure and properties of fibers spun from these resins [21]. In addition, the effect of the spinning speed on the density of fibers, crystallinity, and crystalline and non-crystalline orientation function was investigated. It was found that the density, birefringence, tensile strength, and crystalline and non-crystalline orientation function could be generally improved with increases in the spinning speed. The metallocene iPP fibers were identified to have a breaking tensile strength up to $50 \%$ higher than of the Ziegler-Natta iPP fiber at similar spinning speeds [22]. Therefore, developing metallocene iPP for fiber applications may significantly improve the fiber strength and extend their applications.

It has been reported that the crystallinity and melting temperature of metallocene-catalyzed iPP could be lower than those of conventional iPP fibers, which could be ascribed to the region-defects in the 2,1 and 3,1 insertions. At lower melting temperature, there exist more "tie" molecules between the PP crystallites, which lead to the enhanced tensile strength and elongation at break of metallocene-catalyzed iPP fibers $[6,23]$. Therefore, the metallocene iPP with lower melting temperature is a promising polymer 
for fiber production. In this work, we present a low-melting-temperature metallocene iPP for melt spinning fiber application. The results from a commercial Ziegler-Natta iPP and a metallocene iPP are given for comparison. The structure, thermal properties, and mechanical properties of the three types of iPP are primarily tested. The iPP fibers are fabricated from three iPPs via melt spinning following the same process, and the tensile properties, orientation, and crystallization of the prepared iPP fibers are carefully investigated. The $T_{\mathrm{m}}$ metallocene iPP exhibits remarkable advantages in both the processing and the mechanical performance of the resultant products.

\section{Materials and Methods}

\subsection{Materials}

Isotactic polypropylene sample 1 (iPP-1) is synthesized from $\mathrm{C}_{2}$-symmetric metallocene catalysts (rac-Me $\mathrm{C}_{2} \mathrm{Si}(2-\mathrm{Me}-4-\mathrm{Ph}-\mathrm{Ind})_{2} \mathrm{ZrCl}_{2}$ ) [24] with a $\mathrm{M}_{\mathrm{w}}$ of 147,000 and PDI of 2.5, which is a pilot product synthesized by the China Petroleum Lanzhou Chemical Research Center (Lanzhou, China). Calcium stearate at 500 ppm (Guangdong Wei Lin Na New Material Technology Co. Ltd., Guangzhou, China, $\geq 98 \%$ ), 750 ppm primary antioxidant (Irganox 1010), and 1500 ppm secondary antioxidant (Irgafos 168) (Basf Performance Chemicals (Shanghai) Co. Ltd.) were added into the iPP powder to prepare pellets via extrusion. Isotactic polypropylene sample 2 (iPP-2) is a commercial metallocene PP purchased from Lyondell Basell Industries (Basell HM562S, Rotterdam, Netherlands) with a $\mathrm{M}_{\mathrm{w}}$ of 157,000 and PDI of 2.9. Isotactic polypropylene sample 3 (iPP-3) is a commercial Ziegler-Natta PP produced by Exxon Mobil Corporation (Exxon 3155E3) with a $\mathrm{M}_{\mathrm{w}}$ of 157,000 and PDI of 2.4. All the samples are used as received without any further purification unless notified.

\subsection{Instrumentation and Characterization}

${ }^{13} \mathrm{C}$ NMR spectra were recorded on a Bruker (Advance III) $400 \mathrm{MHz}$ spectrometer with 1,2-dichlorobenzene- $d_{4}$ as the solvent, at $120^{\circ} \mathrm{C}$. Gel permeation chromatography (GPC) was performed on a Waters GPC 1515 HPLC pump (Waters, Milford, MA, USA) and Wyatt DAWN HELEOS-II light scattering/Wyatt Optilab Rex refractive index detectors with 1,2,4-Trichlorobenzene as the eluent and polystyrene as an internal standard, at $135^{\circ} \mathrm{C}$. Differential scanning calorimetric (DSC) analysis was performed on a Netzsch DSC 200 PC (Netzsch, Free State of Bavaria, Germany) in a nitrogen atmosphere at a scanning rate of $15^{\circ} \mathrm{C} \mathrm{min}-1$ from 30 to $180^{\circ} \mathrm{C}$ and the results were collected from the second heating circle. The melt flow rate (MFR) analysis was performed on a Melt Flow Testers 7028 (Ceast, Turin, Italy) according to the GB/T 3682-2000. Tensile properties, bending properties, and impact strength analysis were performed on a universal testing machine 5566 according to the China-National Standard System (GB/T 1040-2006, GB/T 9341-2008 and GB/T 1843-2008, respectively). The crystallization property was performed on a polarizing microscope (POM) DM2500P (Leica, Solms, Germany). The polarized optical microscopic photographs were obtained by using a German Leica DMLP microscope. The temperature-rising elution fractionation (TREF) profiles were generated using Polymer Char 300 TREF (Polymer Char, Valencia, Spain) in a nitrogen atmosphere with 1,2,4-Trichlorobenzene as the solvent. The rheological behavior was studied at $230{ }^{\circ} \mathrm{C}$ by using a capillary rheometer (GOTTFERT, RHEO-TESTER 2000, Berlin, Germany) equipped with a capillary die $(\mathrm{D}=0.5 \mathrm{~mm}, \mathrm{~L} / \mathrm{D}=60)$. The capillary die was sufficiently long so that the Bagley correction was not applied while the Rabinowitsch correction was applied. Crystallization and orientation were evaluated using a 2D wide angle X-ray diffraction (WAXD) (D8 DISCOVER, Bruker, Karlsruhe, Germany) under a voltage of $40 \mathrm{kV}$ and a current of $40 \mathrm{~mA}$ with $\mathrm{Cu} \mathrm{K} \alpha$ radiation $(\lambda=0.154 \mathrm{~nm})$. Thermal analysis was carried out on a differential scanning calorimeter (DSC-I, Mettler Toledo, Switzerland) with samples of ca. $5 \mathrm{mg}$ sealed in aluminum pans heated from 50 to $220^{\circ} \mathrm{C}$ at $10^{\circ} \mathrm{C} \mathrm{min}-1$ in a nitrogen atmosphere. 


\subsection{Melt-Spinning and Hot-Drawing}

The melt-extrusion and spinning were conducted by using a single-screw extruder equipped with a $2.4 \mathrm{~mL} / \mathrm{rev}$ metering-pump and an eight-hole spinneret, and the diameter of each hole was $0.6 \mathrm{~mm}$. The extrusion temperature was set at $215,265,265$, and $265^{\circ} \mathrm{C}$ from the feed zone to the end of the extruder, respectively, and the spinneret temperature was set at $265^{\circ} \mathrm{C}$. The as-spun fibers were taken up at 1200, 2100, and $2750 \mathrm{~m} / \mathrm{min}$, respectively. The as-spun fibers were then hot-drawn by passing through five rollers $(\mathrm{D}=125 \mathrm{~mm})$ and two heat plates $(\mathrm{L}=500 \mathrm{~mm})$ between the $3 \mathrm{rd}$ and 4 th rollers and the 4 th and 5th rollers, respectively. The 2nd, 3rd, and 4th rollers were heated to 70, 130 , and $145^{\circ} \mathrm{C}$, respectively, while the 1 st and 5th rollers were at room temperature. Both the heat plates were kept at $130{ }^{\circ} \mathrm{C}$. For comparison, the winding speed was fixed at $200 \mathrm{~m} / \mathrm{min}$ during drawing, and the total draw ratio (DR) was fixed at 1.6, which was the maximum achievable DR for the fibers spun at the highest speed, i.e., $2750 \mathrm{~m} / \mathrm{min}$.

\section{Results and Discussion}

\subsection{Microstructural Characterization}

The microstructures of the iPP samples (Table 1 ) are determined with solution ${ }^{13} \mathrm{C}$ nuclear magnetic resonance (NMR) spectroscopy analysis. All of the samples are fully regioregular, and no or negligible amounts of regiomistakes are detected in their ${ }^{13} \mathrm{C}$ NMR spectra. They contain stereoregularity defects, which correspond to isolated $r r$ triads, and the number of $r r$ defects depend on the catalyst and polymerization temperature. In Table 1, the contents of the isotactic pentad fraction, namely, $\mathrm{mmmm}$, in the three iPP samples from iPP-1 to iPP-3 are $98.98 \%, 97.10 \%$, and $93.64 \%$ respectively. The highest meso diad content of $98.98 \%$ is observed in iPP-1, which means iPP-1 possesses the highest isotacticity. More or less other types of pentad fractions could be observed in all the three iPP samples. For iPP-1, only two kinds of defect configurations, namely, rmmr and mmrr, could be observed. In comparison with iPP-1, the other two samples have more defect configurations with higher contents. In particular, a high concentration of the fully syndiotactic $r r r r$ pentad is observed in iPP-3. Traditional commercial iPP generally is prepared with the heterogeneous Ziegler-Natta catalytic systems that are composed of multiple sites, and each site may produce polymers with different tacticity. That may address the lower tacticity obtained in the resultant polymer. Different from the Zigler-Natta catalysts, metallocene catalysts are well recognized as single-site systems, which are responsible for the produced polymers with small PDI and high tacticity. For the degradable grade iPP-3 produced by Exxon, the tacticity is much lower than the other two products and more defects could be detected including the highest $m m m r$ and $m m r r$ sequences among the three samples. Even rmrm and $r r r r$ sequences could be found in iPP-3, which is absent in the other two samples. The new metallocene iPP produced in the present work possesses the significant isotacticity advantage over the other two commercial products, which is rather important for the crystallization and properties of the resultant fibers.

Table 1. ${ }^{13} \mathrm{C}$ NMR analysis of the iPP samples.

\begin{tabular}{|c|c|c|c|c|c|c|c|}
\hline Sample & $m m m m \%$ & $m m m r \%$ & $r m m r \%$ & $m m r r \%$ & $m m r m+r m r r \%$ & $r m r m \%$ & $r r r \%$ \\
\hline iPP-1 & $98.98 \%$ & 0 & $0.28 \%$ & $0.74 \%$ & 0 & 0 & 0 \\
\hline iPP-2 & $97.10 \%$ & $1.87 \%$ & 0 & $0.75 \%$ & $0.28 \%$ & 0 & 0 \\
\hline iPP-3 & $93.64 \%$ & $2.85 \%$ & $0.81 \%$ & $2.1 \%$ & 0 & $0.4 \%$ & $0.2 \%$ \\
\hline
\end{tabular}

\subsection{Structural Characterization}

iPP can generally be crystallized in three different polymorphic forms $(\alpha, \beta$, and $\gamma$ forms) characterized by chains in a 3-fold helical conformation, which can be clearly identified by the distinctive reflection in the WAXD scan. The WAXD patterns of several samples for each iPP are shown in Figure 1. We recall that $\alpha$ and $\gamma$ forms of iPP present similar X-ray diffraction (XRD) profiles and 
mainly differ in the position of the third strong diffraction peak, which appears at $2 \theta=18.6^{\circ}\left((130)_{\alpha}\right.$ reflection) in the $\alpha$ form and at $2 \theta=20.1^{\circ}((117) \gamma$, reflection) in the $\gamma$ form. Apparently, the crystalline fractions are mainly crystallized in the $\alpha$ form in all of the iPP samples as indicated by the presence of the $(130)_{\alpha}$ reflection at $2 \theta=18.6^{\circ}$ of the $\alpha$ form and the absence of the $(117)_{\gamma}$ reflection at $2 \theta=20.1^{\circ}$ of the $\gamma$ form in the XRD profiles.

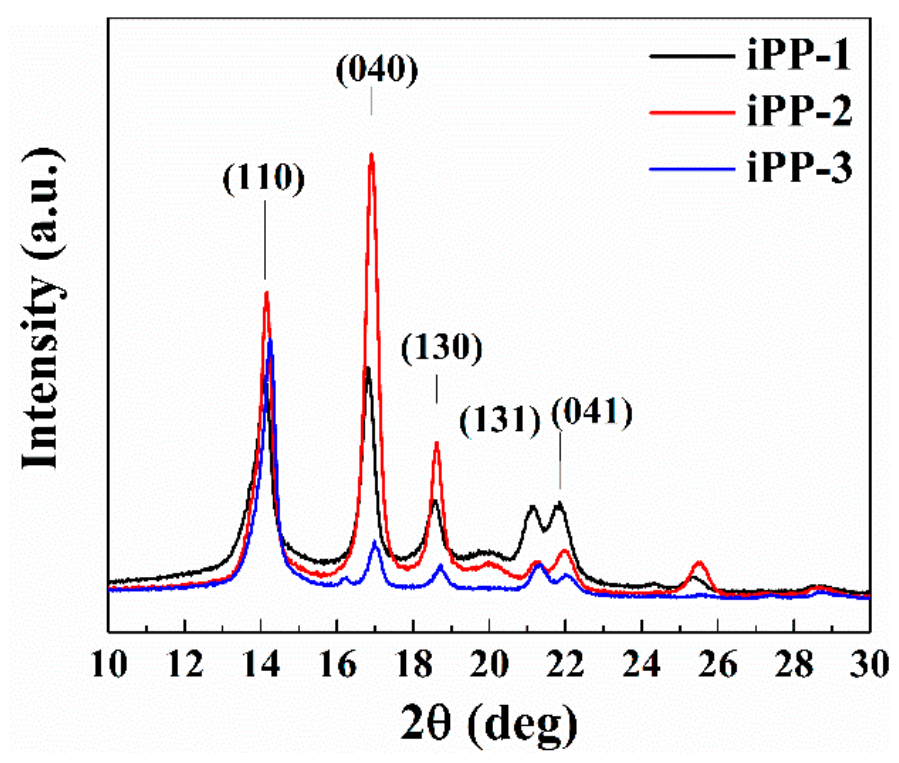

Figure 1. X-ray powder diffraction profiles of as-prepared specimens of the iPP samples.

The thermal analysis of the PP samples was conducted via differential scanning calorimetry (DSC), and the DSC heating curves are shown in Figure 2. All of the samples exhibit broad melting endotherms characterized by a single peak. The iPP-1 has a $T_{\mathrm{m}}$ of $10^{\circ} \mathrm{C}$ lower than the other two samples (Table 1 ), independent of the processing conditions. That confirms the reported results that metallocene iPP possesses lower $T_{m}$ than the other iPPs such as those catalyzed with the Ziegler-Natta catalyst. The crystallinity of the three types of iPP resins is estimated on the basis of the DSC results by using the following equation, $\chi_{\mathrm{c}}=\Delta H_{f} / \Delta H_{f}{ }^{*}$, where $\Delta H_{f}$ and $\Delta H_{f}^{*}(145 \mathrm{~J} / \mathrm{g})$ [25] refer to the melting enthalpies of the iPP resins and iPP with $100 \% \alpha$ form crystallinity, respectively. As listed in Table 2, the crystallinity of iPP-1 (about 51.2\%) is higher than the other iPP resins, which agrees well with the isotacticity results as discussed above. Further, the metallocene catalyzed iPP may possess different types of microstructural defects, such as stereo-defects and region-defects in the polymer chain. Moreover, the traditional Ziegler-Natta catalyst polypropylene have stereo-defects only. The stereo-defects are mainly $r r$ isolated triads, while the region-defects are mainly 2,1 and 3,1 insertions [26,27]. The insertion of regio-irregular units in the main chain leads to a random distribution of the microstructural defects. These defects lower the thickness of the lamellar crystal of the polymer chain, which leads to the metallocene iPP (iPP-1) having lower melting temperatures [28]. 


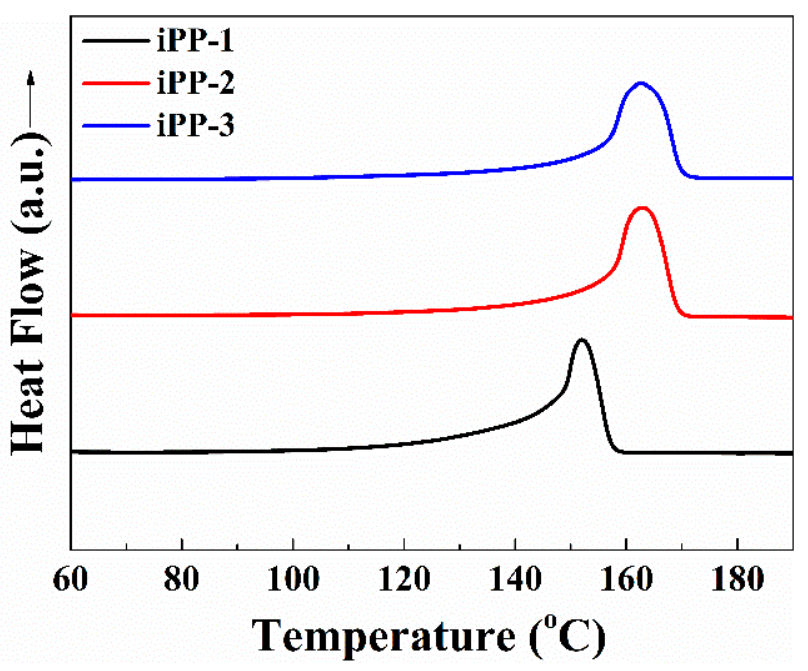

Figure 2. DSC curves of the iPP samples.

Table 2. Melting temperatures $\left(T_{\mathrm{m}}\right)$, melting enthalpies $\left(\Delta H_{\mathrm{m}}\right)$, and crystallinity indices $\left(\chi_{\mathrm{c}}\right)$ of the as-prepared powders of the iPP samples.

\begin{tabular}{cccc}
\hline Sample & iPP-1 & iPP-2 & iPP-3 \\
\hline$T_{\mathrm{m}}\left({ }^{\circ} \mathrm{C}\right)$ & 152.0 & 163.0 & 162.7 \\
$\Delta H_{\mathrm{m}}(\mathrm{J} / \mathrm{g})$ & 74.27 & 73.14 & 71.21 \\
$\chi_{\mathrm{c}}(\%)$ & 51.2 & 50.4 & 49.1 \\
\hline
\end{tabular}

Figure 3 shows the polarized optical microscopy (POM) photographs of the three iPP samples. The commercial iPP (Figure 3b,c) reveals a common spherulitic structure of the $\alpha$ crystal form. However, iPP-1 shows a distorted spherulite shape with a much smaller crystal domain size. That might be ascribed to the addition of calcium stearate to remove the residue acid, which can serve as the nucleating agent for the crystallization of PP as well. As shown in the Figure S1 in the Supplementary Materials, as the temperature decreases, the crystallization is firstly observed in iPP-2 and iPP-3 at $150{ }^{\circ} \mathrm{C}$, while iPP-1 starts to crystallize at $140{ }^{\circ} \mathrm{C}$. Meanwhile, once the crystal nucleus is formed in iPP-2 and iPP-3, the crystal grows gradually along with the slow formation of the new nucleus. However, in iPP-1, a great number of nuclei are formed quickly right from the beginning, and all the nuclei grow simultaneously. The quick formation and growth of the crystal domains are due to the addition of calcium stearate as a nucleating agent resulting in the distorted spherulite domains.

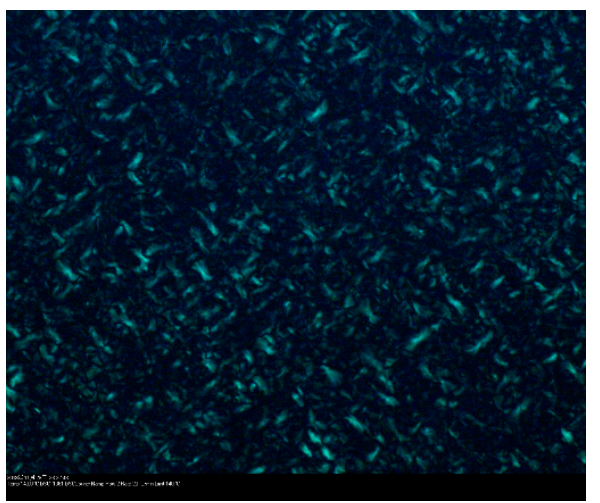

(a) iPP-1

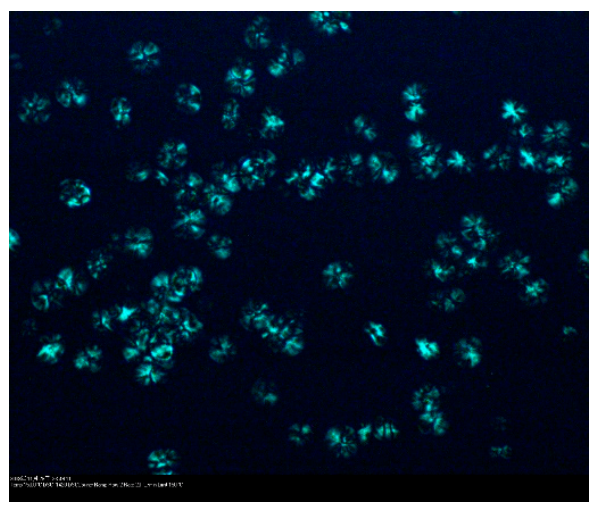

(b) iPP-2

Figure 3. Cont. 


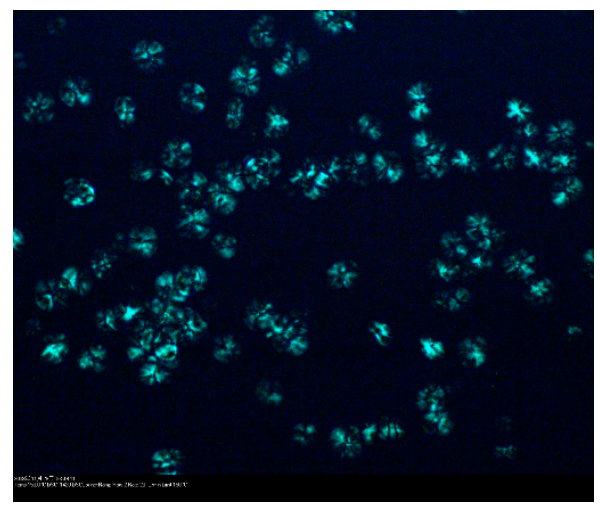

(c) iPP-3

Figure 3. Morphologies of (a) iPP-1, (b) iPP-2 and (c) iPP-3 under a polarizing microscope.

Temperature rising elution fractionation (TREF) is currently the best technique to obtain the composition distribution of polymers with high crystallinity. The difference in the samples is observed in their TREF fractograms as indicated in Figure 4. First of all, the percentages of the soluble fraction eluted at room temperature are $0.3 \%$ for iPP-1, $0.9 \%$ for iPP-2, and $1.3 \%$ for iPP-3 (Table 3). That can be ascribed to the largest iPP-1 isotacticity. For both iPP-2 and iPP-3 samples, the major part of the polymer is eluted at $121{ }^{\circ} \mathrm{C}$, while iPP- 1 is mainly eluted at $115^{\circ} \mathrm{C}$. That could be due to the lower $T_{\mathrm{m}}$ of iPP-1 compared to the other two samples.

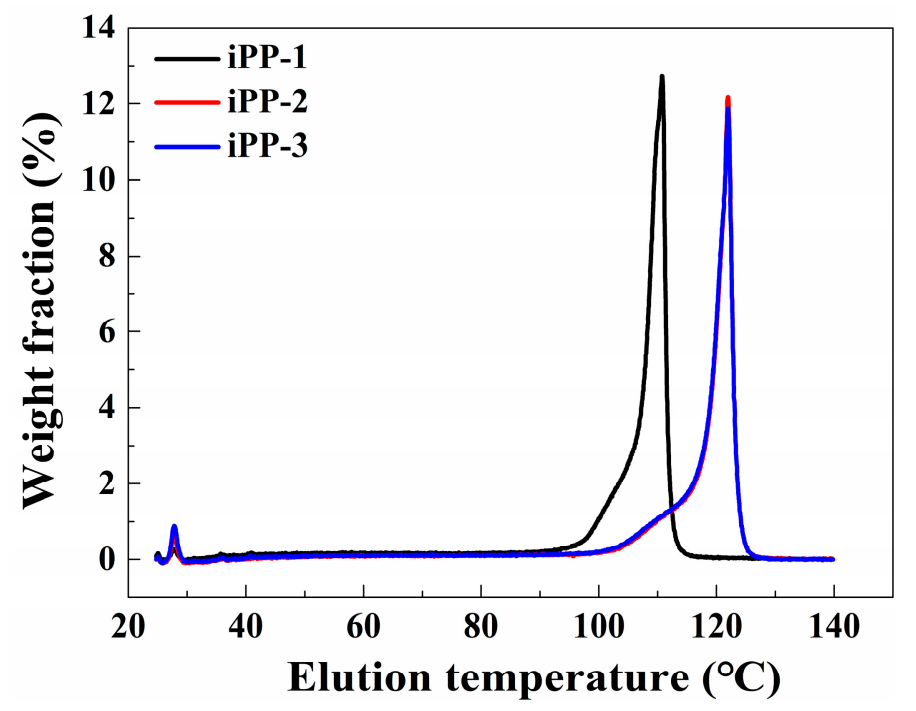

Figure 4. Temperature rising elution fractionation (TREF)curves of the iPP samples.

Table 3. Data of TREF test.

\begin{tabular}{cccc}
\hline Sample & iPP-1 & iPP-2 & iPP-3 \\
\hline Soluble Fractions (\%) & 0.3 & 0.9 & 1.3 \\
\hline
\end{tabular}

\subsection{Mechanical Properties}

The mechanical properties of the iPP samples are tested and summarized in Table 4 . The results indicated that the tensile strength and flexural modulus of the three iPP samples are rather close. The iPP-1 sample exhibits the highest simply supported beam impact strength of $2.15 \mathrm{~kJ} / \mathrm{cm}^{2}$ and the highest elongation at break of $16.21 \%$ because the iPP-1 sample has the highest isotacticity and crystallinity. 
Table 4. Mechanical properties of the iPP samples.

\begin{tabular}{ccccc}
\hline Sample & $\begin{array}{c}\text { Tensile Strength } \\
\mathbf{( M P a )}\end{array}$ & $\begin{array}{c}\text { Flexural Modulus } \\
\mathbf{( M P a )}\end{array}$ & $\begin{array}{c}\text { Simply Supported Beam } \\
\text { Impact Strength } \mathbf{( k J / \mathbf { c m } ^ { 2 } )}\end{array}$ & $\begin{array}{c}\text { Elongation at } \\
\text { Break (\%) }\end{array}$ \\
\hline iPP-1 & 34.7 & 1654 & 2.15 & 16.21 \\
iPP-2 & 35.3 & 1668 & 1.91 & 15.87 \\
iPP-3 & 35.3 & 1496 & 1.89 & 13.48 \\
\hline
\end{tabular}

\subsection{Processing Properties}

Factors affecting the processing properties of PP mainly include the melt flow rate, ash content, and rheological property, and the results of the three samples are shown in Figure 5 and Table 5. In Figure 5, at low-frequency $(100-500 \mathrm{~Hz})$, the viscosity of the iPP samples is decreasing in the order of iPP-2 > iPP-1 > iPP-3. The lower viscosity of iPP-1 compared to iPP-2 could be attributed to the lower $T_{m}$ of iPP-1. The higher viscosity of iPP-1 compared to iPP-3 might be ascribed to the larger isotacticity and crystallinity of iPP-1 compared iPP-3. As the frequency increases, the viscosity of all the samples shows an invisible difference. The production of PP nonwoven fabric requires a melt flow rate between 30 and $40 \mathrm{~g}$ 10/min. As shown in Table 5, all iPP samples with MFR from 34-36 g 10/min meet that requirement. The ash content remarkably influences the stability of the spinning, and the results indicated that all of the PP samples could satisfy this requirement, and the iPP-1 sample has the lowest ash content (Table 5).

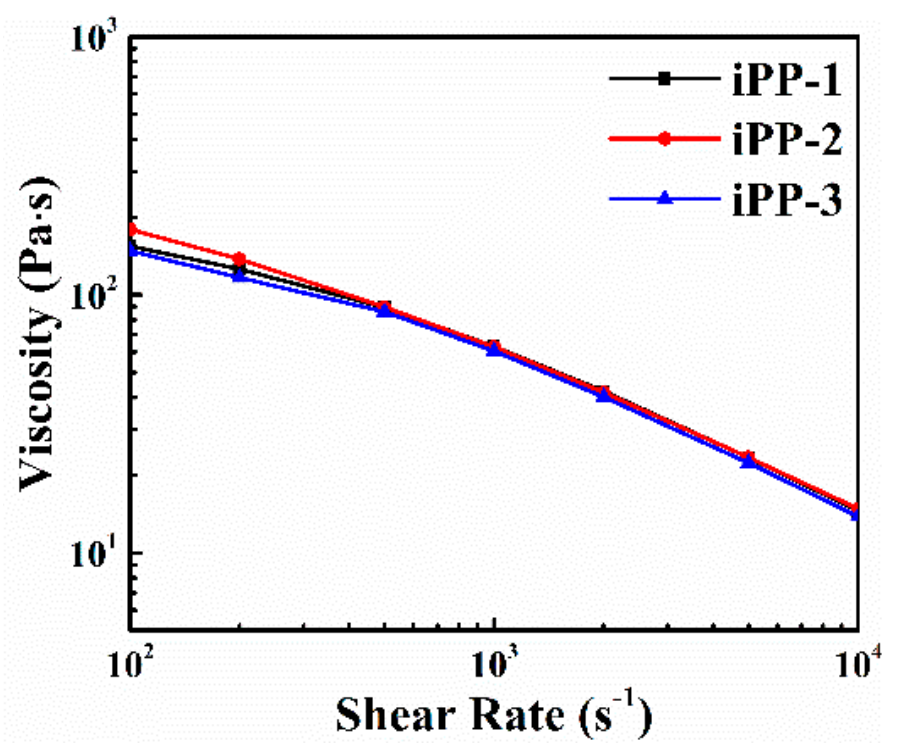

Figure 5. Rheological properties of the iPP samples.

Table 5. Processing properties of the iPP samples.

\begin{tabular}{cccc}
\hline Sample & iPP-1 & iPP-2 & iPP-3 \\
\hline MFR $(\mathrm{g} \mathrm{10/min})$ & 34 & 36 & 35 \\
Ash content $(\mathrm{ppm})$ & 180 & 237 & 220 \\
\hline
\end{tabular}

\subsection{Fiber Properties}

All of the three types of iPP resins were subjected to conventional melt extrusion and spinning, and showed good spinnability within a wide range of take-up speeds (1200-2750 m/min). Tensile tests were performed to evaluate the mechanical properties of the iPP fibers prepared in the present work. The tensile properties of the as-spun and hot-drawn iPP fibers are listed in Tables 6 and 7, respectively. 
In Table 6, the tenacity of the as-spun fiber of iPP- 1 constantly decreases from $1.69 \mathrm{cN} / \mathrm{dtex}$ to $1.22 \mathrm{cN} / \mathrm{dtex}$ as the take-up speed increases from 1200 to $2750 \mathrm{~m} / \mathrm{min}$. However, for the other two samples (iPP-2 and iPP-3), the tenacity decreases initially as the take-up speed increases from 1200 to $2100 \mathrm{~m} / \mathrm{min}$ and increases subsequently as the take-up speed further increases to $2750 \mathrm{~m} / \mathrm{min}$. Such inconsistencies are also observed in the trend of modulus varying with the take-up speed for the three types of samples (Table 6). At a given take-up speed, the as-spun fibers prepared using iPP-1 show lower tenacity and modulus than those of the other two samples in most cases. The elongation at break of all the samples decreases constantly as the take-up speed increases. At a given take-up speed, the as-spun fibers prepared using iPP-1 show intermediate elongation at break between the two other types of the samples.

For the fiber samples, tenacity is dominated mainly by molecular orientation, whereas modulus is dominated mostly by structural perfection (orientation and crystallization). During melt spinning, multiple factors control molecular orientation and structural perfection, manifested by various parameters, such as tension, strain rate, and cooling rate in the thread line. Although all of these parameters increase as the take-up speed increases, different impacts are observed. For instance, the increased tension and the strain rate may promote molecular orientation, but the increment in the cooling rate may freeze the molecular chains too rapidly to provide enough time and mobility for their orientation and crystallization. We attempt to explain the observed variations in fiber properties in the succeeding discussion by considering the fiber structures developed under various conditions.

Table 6. Tensile properties of as-spun iPP fibers.

\begin{tabular}{cccccc}
\hline Sample & $\begin{array}{c}\text { Take-up Speed } \\
\text { (m/min) }\end{array}$ & $\begin{array}{c}\text { Line Density } \\
\text { (dtex) }\end{array}$ & $\begin{array}{c}\text { Tenacity } \\
\text { (cN/dtex) }\end{array}$ & $\begin{array}{c}\text { Modulus } \\
\text { (cN/dtex) }\end{array}$ & $\begin{array}{c}\text { Elongation at } \\
\text { Break (\%) }\end{array}$ \\
\hline \multirow{2}{*}{ iPP-1 } & 1200 & 97.5 & 1.69 & 12.0 & 242.5 \\
& 2100 & 91.8 & 1.37 & 16.4 & 157.1 \\
iPP-2 & 2750 & 88.9 & 1.22 & 15.6 & 120.0 \\
\hline \multirow{3}{*}{ iPP-3 } & 1200 & 84.0 & 1.77 & 12.8 & 460.8 \\
& 2100 & 91.8 & 1.60 & 16.8 & 207.3 \\
& 2750 & 86.8 & 1.67 & 17.1 & 165.7 \\
\hline
\end{tabular}

In synthetic fiber and textile industries, hot-drawing treatment is usually performed to further improve the properties of fibers and stabilize their fiber. As a general rule, tenacity and modulus increase, but the elongation at break decreases as the draw ratio (DR) increases. A low take-up speed for the as-spun fibers indicates a highly achievable DR during hot drawing. In the present work, we chose a low and constant DR of 1.6 to ensure a practical drawing process for the as-spun fibers and to fairly compare them.

In Table 7, the tenacity of the drawn fiber is significantly increased compared to the as-spun fiber. The modulus of the drawn fibers is also increased in most cases. The line density and the elongation at break of the drawn fibers are notably decreased. These changes are consistent with the general rule of fiber drawing. In other words, the fiber becomes thinner, stronger, and more rigid upon hot drawing, and these property values in the present work are acceptable for general textile applications. For the as-spun fibers prepared at low take-up speeds, DR exceeding 1.6 can be readily applied during hot drawing, and fibers with high tenacity and modulus can be produced if needed. 
Table 7. The tensile properties of drawn iPP fibers (draw ratio: 1.6).

\begin{tabular}{cccccc}
\hline Sample & $\begin{array}{c}\text { Take-up Speed } \\
\text { (m/min) }\end{array}$ & $\begin{array}{c}\text { Line Density } \\
\text { (dtex) }\end{array}$ & $\begin{array}{c}\text { Tenacity } \\
\text { (cN/dtex) }\end{array}$ & $\begin{array}{c}\text { Modulus } \\
\text { (cN/dtex) }\end{array}$ & $\begin{array}{c}\text { Elongation at } \\
\text { Break (\%) }\end{array}$ \\
\hline \multirow{2}{*}{ iPP-1 } & 1200 & 52.6 & 2.98 & 21.1 & 28.0 \\
& 2100 & 56.2 & 2.63 & 18.0 & 30.8 \\
\hline \multirow{2}{*}{ iPP-2 } & 2750 & 53.6 & 2.57 & 19.9 & 19.8 \\
\hline \multirow{3}{*}{ iPP-3 } & 1200 & 54.0 & 2.47 & 15.7 & 91.1 \\
& 2100 & 56.5 & 2.47 & 13.8 & 78.0 \\
& 2750 & 51.9 & 3.45 & 22.4 & 34.1 \\
\hline
\end{tabular}

\subsection{Thermal Properties of Fibers Produced}

Thermal properties are essential for fibers to determine the appropriate processing and usage temperature windows. Figure 6 shows the DSC thermograms of the as-spun and drawn fibers during the first heating run. In all the thermograms, distinct endothermic melting peaks that are wide or split and have shoulders are observed, implying that all of the fiber samples are crystalline but have complex crystal forms or morphologies. The iPP is well known to be able to crystallize into multiple forms, such as $\alpha, \beta$, and $\gamma$, under different conditions. If the cooling rate is high, typically encountered in high-speed spinning, iPP may form a mesomorphic phase with its structure close to the $\alpha$ crystal except with an imperfect chain organization. Therefore, having a complex crystalline or mesomorphic structures for the iPP fibers is not surprising because complex thermal and tension histories are experienced during melt spinning and hot drawing.

Melting peaks are separated using PeakFit to derive a series of Gaussian subpeaks (Tables 8 and 9) and to perform a relevant quantitative analysis. Interestingly, the melting peaks of the fibers prepared using iPP-1 can be separated into three subpeaks, whereas those of the two other types of fibers can be divided into two subpeaks. This result may be due to the presence of a nucleating agent (calcium stearate) that induces the formation of small crystals with the lowest $T_{\mathrm{m}, 3}\left(143.8-151.5^{\circ} \mathrm{C}\right)$ in iPP-1. The fibers prepared with iPP- 1 have $T_{\mathrm{m}, 1}$ of $159.8-162.4{ }^{\circ} \mathrm{C}$ and $T_{\mathrm{m}, 2}$ of $151.3-156.8^{\circ} \mathrm{C}$, which are significantly lower than those of the two other types of samples (iPP-2 and iPP-3) for the lower $T_{\mathrm{m}}$ of the pristine iPP-1 resin.

Table 8. Sub-peaks derived from DSC curves for as-spun iPP fibers.

\begin{tabular}{|c|c|c|c|c|c|}
\hline Sample & Take-up Speed (m/min) & $T_{\mathrm{m}, 1}\left({ }^{\circ} \mathrm{C}\right)$ & $T_{\mathrm{m}, 2}\left({ }^{\circ} \mathrm{C}\right)$ & $T_{\mathrm{m}, 3}\left({ }^{\circ} \mathrm{C}\right)$ & $f\left(\mathbf{R}^{2}\right)$ \\
\hline \multirow{3}{*}{ iPP-1 } & 1200 & 160.3 & 151.3 & 148.7 & $99.82 \%$ \\
\hline & 2100 & 159.8 & 152.4 & 148.5 & $99.88 \%$ \\
\hline & 2750 & 160.6 & 153.4 & 151.4 & $99.94 \%$ \\
\hline \multirow{3}{*}{ iPP-2 } & 1200 & 173.4 & 165.8 & $\mathrm{n} / \mathrm{a}$ & $99.56 \%$ \\
\hline & 2100 & 171.4 & 163.9 & $\mathrm{n} / \mathrm{a}$ & $99.02 \%$ \\
\hline & 2750 & 171.8 & 163.1 & $\mathrm{n} / \mathrm{a}$ & $99.40 \%$ \\
\hline \multirow{3}{*}{ iPP-3 } & 1200 & 171.1 & 163.8 & $\mathrm{n} / \mathrm{a}$ & $99.66 \%$ \\
\hline & 2100 & 172.7 & 165.2 & $\mathrm{n} / \mathrm{a}$ & $99.87 \%$ \\
\hline & 2750 & 171.0 & 162.4 & $\mathrm{n} / \mathrm{a}$ & $99.84 \%$ \\
\hline
\end{tabular}


Table 9. Sub-peaks derived from DSC curves for drawn iPP fibers.

\begin{tabular}{cccccc}
\hline Sample & Take-up Speed (m/min) & $\mathbf{T}_{\mathbf{m}, \mathbf{1}}\left({ }^{\circ} \mathbf{C}\right)$ & $\boldsymbol{T}_{\mathbf{m}, \mathbf{2}}\left({ }^{\circ} \mathbf{C}\right)$ & $\boldsymbol{T}_{\mathbf{m}, \mathbf{3}}\left({ }^{\circ} \mathbf{C}\right)$ & $f\left(\mathbf{R}^{\mathbf{2}}\right)$ \\
\hline \multirow{2}{*}{ iPP-1 } & 1200 & 162.4 & 153.4 & 149.1 & $99.90 \%$ \\
& 2100 & 161.7 & 156.8 & 151.5 & $99.47 \%$ \\
\hline \multirow{2}{*}{ iPP-2 } & 2750 & 161.2 & 153.1 & 143.8 & $99.95 \%$ \\
& 1200 & 173.4 & 165.8 & n/a & $99.56 \%$ \\
& 2100 & 171.4 & 163.9 & n/a & $99.02 \%$ \\
iPP-3 & 2750 & 171.8 & 163.1 & n/a & $99.40 \%$ \\
& 1200 & 174.2 & 166.4 & n/a & $99.85 \%$ \\
& 2100 & 174.9 & 165.4 & n/a & $99.85 \%$ \\
& 2750 & 171.3 & 162.5 & n/a & $99.49 \%$ \\
\hline
\end{tabular}
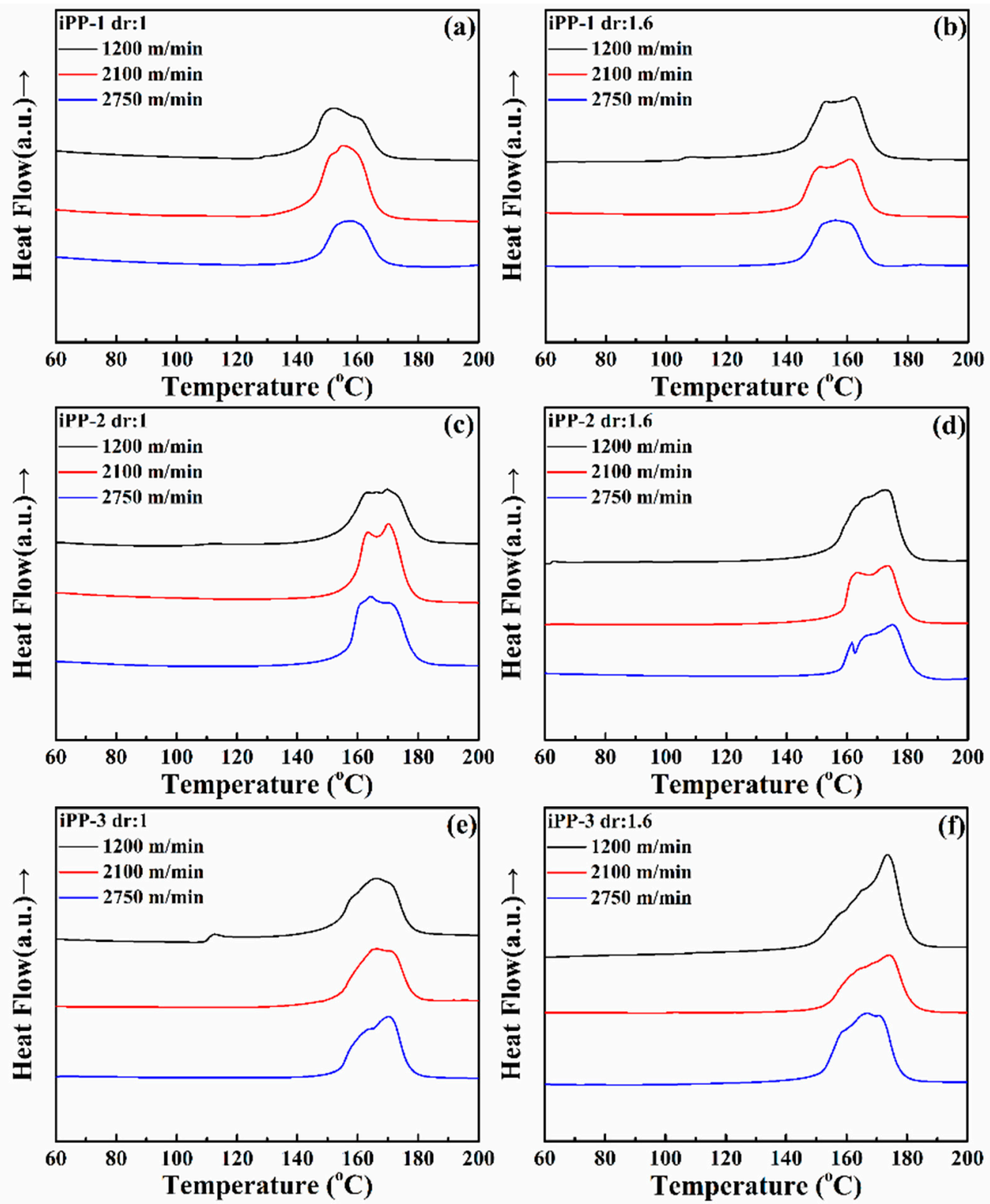

Figure 6. DSC thermograms of (a), (c), (e) as-spun and (b), (d), (f) drawn iPP fibers. 


\subsection{Orientation and Crystallization}

2D-WAXD is used as a nondestructive tool to characterize the orientation and crystallization of various fibers. Figures 7 and 8 (and Figures S2 and S3) show the 2D-WAXD patterns of the as-spun and drawn fibers, respectively. In Figure 7, diffraction arcs are observed in the patterns of the as-spun fibers prepared at low take-up speeds, thereby transforming into bright and sharp spots at high take-up speeds. This finding suggests that the orientation and crystallization of the as-spun fibers are significantly improved as the take-up speed increases. For the drawn fibers (Figure 8), all of the 2D-WAXD patterns are featured by bright and sharp spots, indicating that these samples are highly oriented and crystallized during hot drawing.

$1200 \mathrm{~m} / \mathrm{min}$

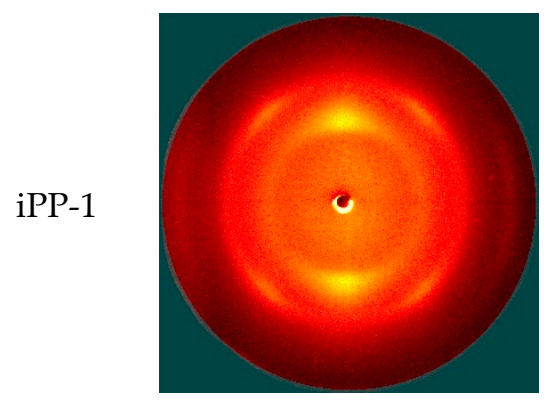

iPP-2
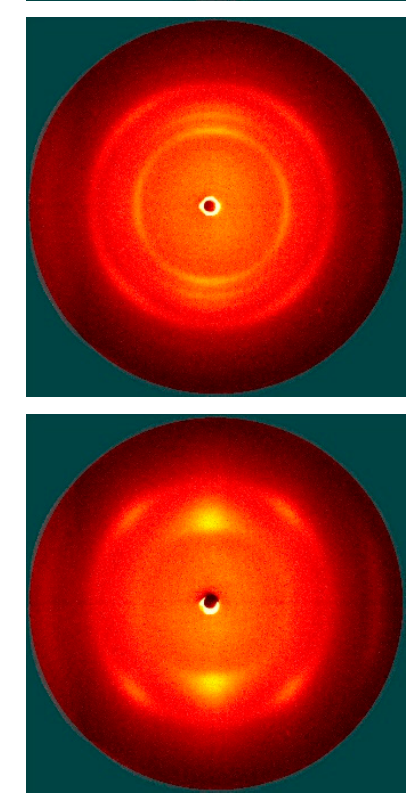

iPP-3
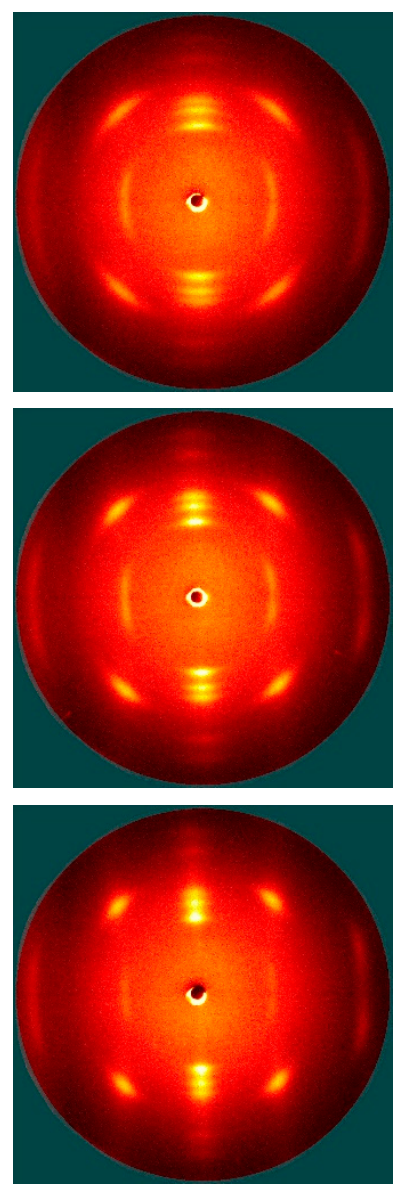

Figure 7. 2D-WAXD patterns of as-spun iPP fibers. 
$1200 \mathrm{~m} / \mathrm{min}$
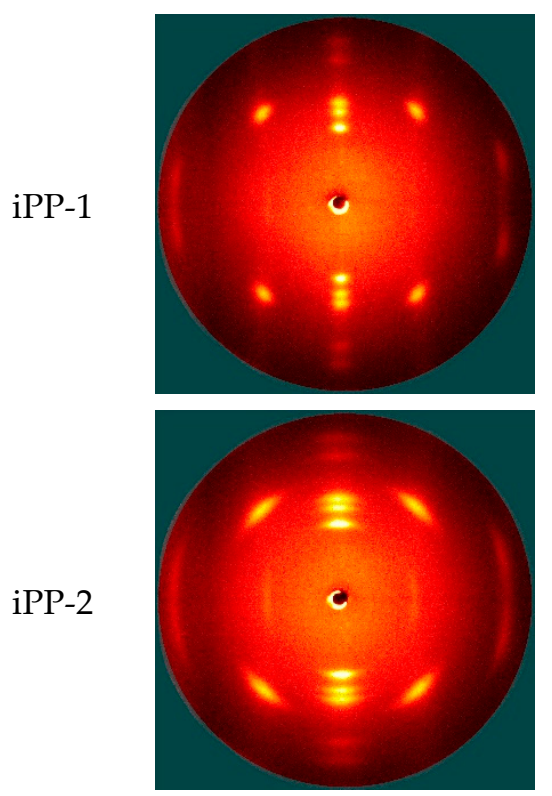

iPP-2

iPP-3

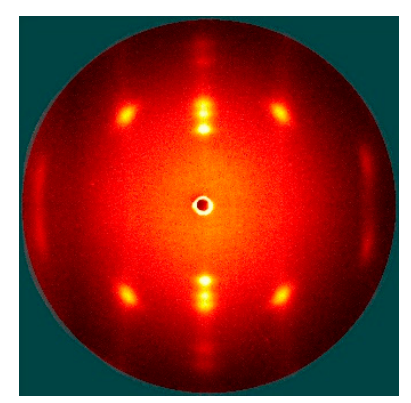

$2750 \mathrm{~m} / \mathrm{min}$
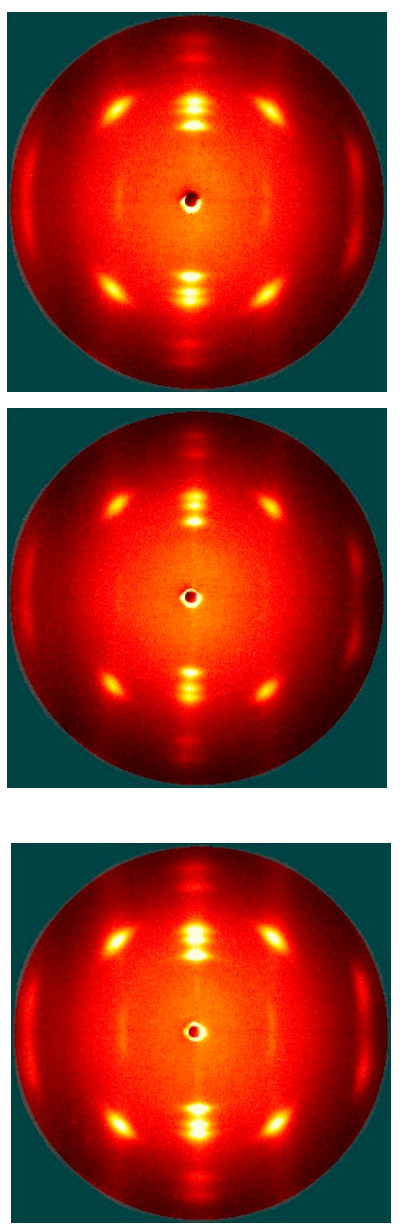

Figure 8. 2D WAXD patterns of drawn iPP fibers (draw ratio: 1.6).

The DSC data show the complex crystalline or the formation of mesomorphic structures of the as-spun and drawn fibers. The 2D-WAXD patterns are integrated into 1D curves (Figure 9, Figure 10, Figures S4 and S5) to clarify this condition. Notably, most of the samples exhibit distinct crystalline diffraction peaks at $14.2^{\circ}, 16.8^{\circ}, 18.5^{\circ}, 21.2^{\circ}$, and $21.8^{\circ}$ corresponding to the (110), (040), (130), (111), and (041) planes of the $\alpha$ crystal, respectively. Two exceptions are observed, that is, the as-spun fibers (iPP-1 and iPP-3) prepared at a low take-up speed $(1200 \mathrm{~m} / \mathrm{min})$ have two wide peaks at ca. $15^{\circ}$ and $21.3^{\circ}$ corresponding to the mesomorphic phase. The mesomorphic peaks are close to those of the $\alpha$ crystal. As such, the coexistence of the mesomorphic phase and the $\alpha$ crystal is possible, especially for the as-spun fibers. By contrast, a less mesomorphic phase should exist in the drawn fibers because it would be transformed into the $\alpha$ crystal during hot drawing. 
$1200 \mathrm{~m} / \mathrm{min}$
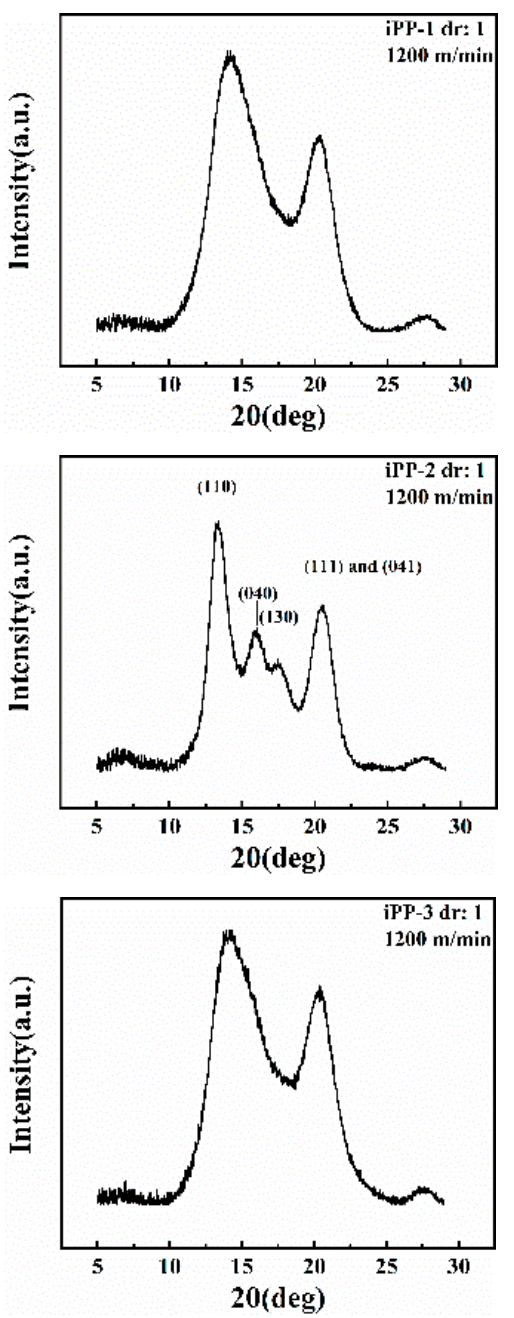

$2750 \mathrm{~m} / \mathrm{min}$
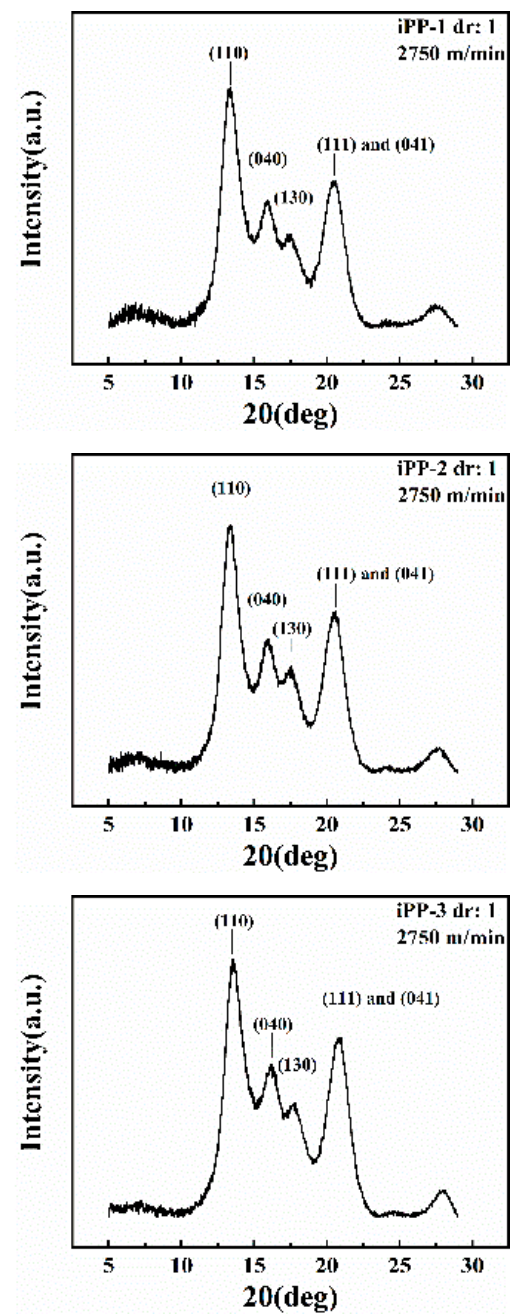

Figure 9. 1D WAXD curves of as-spun iPP fibers.

A close examination of the 1D-WAXD curves shown in Figures 9 and 10 (Figures S4 and S5) provides further details. First, for the as-spun fibers, the peaks corresponding to the planes of the $\alpha$ crystal, especially those of the (040) and (130) planes, intensify and become sharp as the take-up speed increases, suggesting that the formation of the $\alpha$ crystal is favored by the high tension at a high take-up speed. Second, for the drawn fibers, the peaks corresponding to the planes of the $\alpha$ crystal further become sharp, suggesting a constant perfection of crystallization during hot drawing. Lastly, for the as-spun fibers prepared at a low take-up speed $(1200 \mathrm{~m} / \mathrm{min})$, the crystallization behavior reflected by the WAXD data is quite different among the three types of fibers. Specifically, iPP- 1 and iPP-3 show a relatively slow crystallization behavior and form the mesomorphic phase, whereas iPP-2 exhibits a rapid crystallization behavior and readily produces the $\alpha$ crystal. 
$1200 \mathrm{~m} / \mathrm{min}$
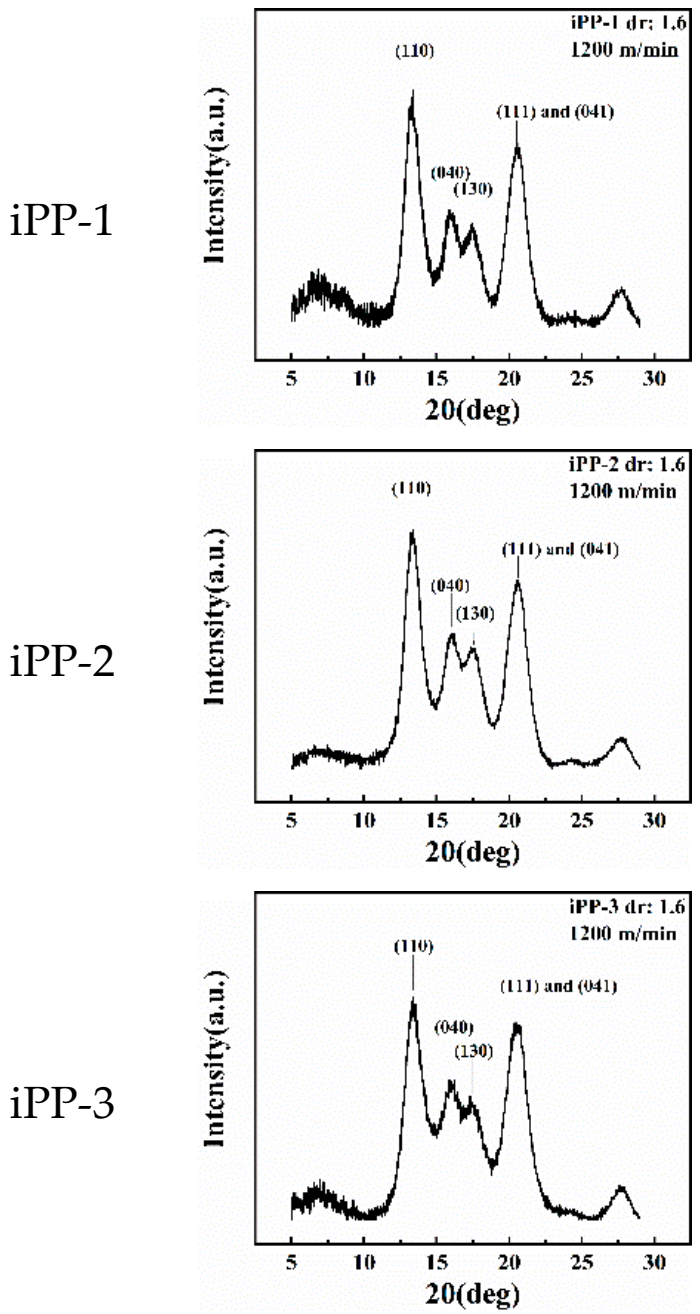

$2750 \mathrm{~m} / \mathrm{min}$
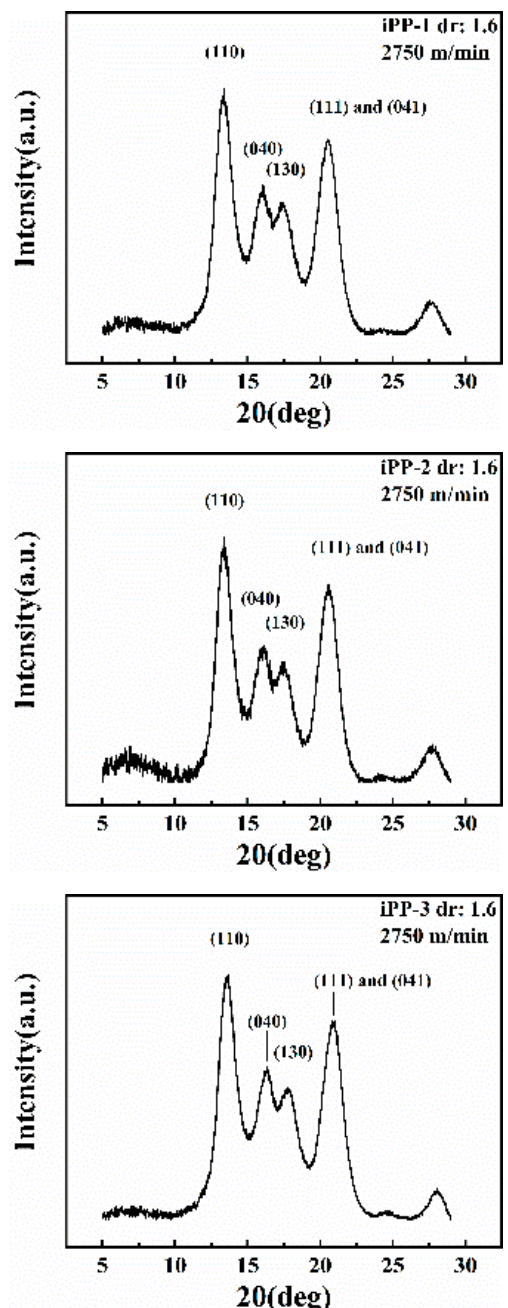

Figure 10. 1D-WAXD curves of drawn iPP fibers (draw ratio: 1.6).

\section{Conclusions}

In summary, the structure, properties, and feasibility of producing fibers from a newly developed metallocene iPP resin have been carefully tested by comparing them with the commercial products. The influence of crystalline properties on the processing ability along with the mechanical properties of melt spinning fibers are well discussed. The low $T_{\mathrm{m}}$ and high isotacticity of iPP- 1 are responsible for its advantages both in the fabrication conditions and the properties of the fibers. The newly developed iPP is confirmed to be a promising candidate for producing high-performance fibers from the melt spinning process.

Supplementary Materials: The following are available online at http://www.mdpi.com/2073-4360/11/4/729/s1, Figure S1: Morphologies of the iPP samples under a polarizing microscope, Figure S2: 2D WAXD patterns of as-spun iPP fibers, Figure S3: 2D WAXD patterns of drawn iPP fibers (draw ratio: 1.6), Figure S4: 1D WAXD curves of as-spun iPP fibers, Figure S5: 1D WAXD curves of drawn iPP fibers (draw ratio: 1.6).

Author Contributions: R.X., P.Z., and X.C. performed the experiments; J.X. and J.S. analyzed the data and wrote the paper; and H.W., P.C., and Z.Z. conceived and designed the experiments.

Funding: This work was financially supported by the National Nature Science Foundation of China (Grant No. $51773166,51573146,51103115,51603167)$, the Key Laboratory Construction Program of Xi'an Municipal Bureau of Science and Technology (201805056ZD7CG40), the Foundation of National Ministry and Commission (No. 613262), 
Fundamental Research Funds for the Central Universities (No. XJJ2016002, cxtd2015003), the Natural Science Basic Research Plan in Shaanxi Province of China (No. 2016JQ2010), and the China Postdoctoral Science Foundation Funded Project (2015M582633).

Conflicts of Interest: The authors declare no conflict of interest.

\section{References}

1. Cho, D.; Zhou, H.; Cho, Y.; Audus, D.; Joo, Y.L. Structural properties and superhydrophobicity of electrospun polypropylene fibers from solution and melt. Polymer 2010, 51, 6005-6012. [CrossRef]

2. Noumowe, A. Mechanical properties and microstructure of high strength concrete containing polypropylene fibres exposed to temperatures up to $200^{\circ} \mathrm{C}$. Cem. Concr. Res. 2005, 35, 2192-2198. [CrossRef]

3. Chadwick, J.C.; Burgt, F.P.J.T.; Rastogi, S.; Busico, V.; Cipullo, R.; Talarico, G.; Heere, J.J.R. Influence of Ziegler-Natta catalyst regioselectivity on polypropylene molecular weight distribution and rheological and crystallization behavior. Macromolecules 2004, 37, 9722-9727. [CrossRef]

4. Niu, H.; Wang, Y.J.; Liu, X.Y.; Wang, Y.S.; Li, Y. Determination of plateau moduli and entanglement molecular weights of ultra-high molecular weight isotactic polypropylene synthesized by Ziegler-Natta catalyst. Polym. Test. 2017, 60, 260-265. [CrossRef]

5. Resconi, L.; Cavallo, L.; Fait, A.; Piemontesi, F. Selectivity in propene polymerization with metallocene catalysts. Chem. Rev. 2000, 100, 1253-1346. [CrossRef]

6. Hammerschmid, K.; Gahleitner, M. Polypropylene, an A-Z Reference; Springer: Delft, The Netherlands, 1999.

7. Osta, A.R.; Picu, R.C.; Isele, O.; Hamm, R. Structural evolution and mechanical properties of iPP melt spun fibers subjected to thermal treatment. J. Polym. Res. 2016, 23, 59-71. [CrossRef]

8. Sowinski, P.; Piorkowska, E.; Boyer, S.A.; Haudin, J.M. On the structure and nucleation mechanism in nucleated isotactic polypropylene crystallized under high pressure. Polymer 2018, 151, 179-186. [CrossRef]

9. De Rosa, C.; Auriemma, F.; Circelli, T. Crystallization of the $\alpha$ and $\gamma$ forms of isotactic polypropylene as a tool to test the degree of ssegregation of defects in the polymer chains. Macromolecules 2002, 35, 3622-3629. [CrossRef]

10. Wang, Y.; Zhao, J.; Qu, M.J.; Guo, J.; Yang, S.G.; Lei, J.; Xu, J.Z.; Chen, Y.H.; Li, Z.M.; Hsiao, B.S. An unusual promotion of $\gamma$-crystals in metallocene-made isotactic polypropylene from orientational relaxation and favorable temperature window induced by shear. Polymer 2018, 134, 196-203. [CrossRef]

11. Mileva, D.; Androsch, R.; Zhuravlev, E.; Schick, C. Temperature of melting of the mesophase of isotactic polypropylene. Macromolecules 2009, 42, 7275-7278. [CrossRef]

12. Silvestre, C.; Cimmino, S.; Duraccio, D.; Schick, C. Isothermal crystallization of isotactic poly(propylene) studied by superfast calorimetry. Macromol. Rapid Commun. 2007, 28, 875-881. [CrossRef]

13. Androsch, R.; Laur, M.; Lorenzo, D.; Schick, C.; Wunderlich, B. Mesophases in polyethylene, polypropylene, and poly(1-butene). Polymer 2010, 51, 4639-4662. [CrossRef]

14. Zhang, X.Q.; Li, R.B.; Kong, L.; Wang, D.J. Stress-induced structure transition of syndiotactic polypropylene via melt spinning. Polymer 2008, 49, 1350-1355. [CrossRef]

15. Schimanski, T.; Peijs, T.; Lemstra, P.J.; Loos, J. Influence of postdrawing temperature on mechanical properties of melt-Spun isotactic polypropylene. Macromolecules 2004, 37, 1810-1815. [CrossRef]

16. Loos, J.; Schimanski, T. Effect of postdrawing temperature on structure, morphology, and mechanical properties of melt-spun isotactic polypropylene tapesm. Macromolecules 2005, 38, 10678-10685. [CrossRef]

17. Dogan, F. Polypropylene; InTech: Rijeka, Croatia, 2012; pp. 483-500.

18. De Santis, F.; Adamovsky, S.; Titomanlio, G.; Schick, C. Scanning nanocalorimetry at high cooling rate of isotactic polypropylene. Macromolecules 2006, 39, 2562-2567. [CrossRef]

19. Zia, Q.; Androsch, R.; Radusch, H.J.; Piccarolo, S. Morphology, reorganization and stability of mesomorphic nanocrystals in isotactic polypropylene. Polymer 2006, 47, 8163-8172. [CrossRef]

20. Arvidson, S.A.; Khan, S.A.; Gorga, R.E. Mesomorphic- $\alpha$-monoclinic phase transition in isotactic polypropylene: A study of processing effects on structure and mechanical properties. Macromolecules 2010, 43, 2916-2924. [CrossRef]

21. Bond, E.B.; Spruiell, J.E. Melt spinning of metallocene catalyzed polypropylenes. I. On-line measurements and their interpretation. J. Appl. Polym. Sci. 2001, 82, 3223-3236. [CrossRef] 
22. Bond, E.B.; Spruiell, J.E. Melt spinning of metallocene catalyzed polypropylenes. II. As-spun filament structure and properties. J. Appl. Polym. Sci. 2001, 82, 3237-3247. [CrossRef]

23. Marcincin, A.; Ujhelyioval, A.; Marcincin, K.; Hricova, M. Spinning, mechanical and thermal properties of metallocene polypropylene fibers. J. Therm. Anal. Calorim. 2016, 123, 1329-1341. [CrossRef]

24. Spaleck, W.; Kueber, F.; Winter, A.; Rohrmann, J.; Bachmann, B.; Antberg, M.; Dolle, V.; Paulus, E.F. The influence of aromatic substituents on the polymerization behavior of bridged zirconocene catalysts. Organometallics 1994, 13, 954-963. [CrossRef]

25. Labour, T.; Gauthier, C.; Seguela, R.; Vigier, G.; Bomal, Y.; Orange, G. Influence of the $\beta$ crystalline phase on the mechanical properties of unfilled and $\mathrm{CaCO}_{3}$-filled polypropylene. I. Structural and mechanical characterization. Polymer 2001, 42, 7127-7135. [CrossRef]

26. Rosa, D.C.; Auriemma, F.; Circelli, T.; Longo, P.; Boccia, A.C. Stereoblock polypropylene from a metallocene catalyst with a hapto-flexible naphthyl-indenyl ligand. Macromolecules 2003, 36, 3465-3474. [CrossRef]

27. Alamo, R.G.; Kim, M.H.; Galante, M.J.; Isasi, J.R.; Mandelkern, L. Structural and kinetic factors governing the formation of the $\gamma$ polymorph of isotactic polypropylene. Macromolecules 1999, 32, 4050-4064. [CrossRef]

28. Chang, H.F.; Zhang, Y.; Ren, S.T.; Dang, X.F.; Zhang, L.Y.; Li, H.Y.; Hu, Y.L. Study on the sequence length distribution of polypropylene by the successive self-nucleation and annealing (SSA) calorimetric technique. Polym. Chem. 2012, 3, 2909-2919. [CrossRef]

(C) 2019 by the authors. Licensee MDPI, Basel, Switzerland. This article is an open access article distributed under the terms and conditions of the Creative Commons Attribution (CC BY) license (http://creativecommons.org/licenses/by/4.0/). 